\title{
Parental beliefs about children's teething in Udaipur, India: a preliminary study
}

\author{
Gauri Kakatkar(a) \\ Ramesh Nagarajappa ${ }^{(a)}$ \\ Nagesh Bhat ${ }^{(b)}$ \\ Vikas Prasad(c) \\ Archana Sharda(a) \\ Kailash Asawa(a) \\ (a) Public Health Dentistry, Pacific Dental \\ College, Udaipur, India. \\ (b) Public Health Dentistry, Darshan Dental \\ College, Udaipur, India. \\ (c) Oral Pathology and Microbiology, Darshan \\ Dental College, Udaipur, India.
}

Declaration of Interests: The authors certify that they have no commercial or associative interest that represents a conflict of interest in connection with the manuscript.

Corresponding Author:

Gauri Kakatkar

Email:gaurikaks@yahoo.co.in

Received for publication on Sep 15, 2011 Accepted for publication on Dec 20, 2011

\begin{abstract}
Throughout history, teething has been held responsible for a variety of childhood illnesses. The objective of this study was to assess parents' knowledge and beliefs about teething signs and symptoms and to investigate the practices used to alleviate teething troubles. A crosssectional survey was conducted using a self-administered questionnaire distributed to 550 parents in Udaipur, India. The questionnaire contained three sections eliciting demographic characteristics and assessing parents' knowledge, beliefs, and practices regarding teething. Statistical analysis used descriptive statistics and the chi-squared test $(p \leq 0.05)$. Response to teething was incorrectly attributed to fever $(70 \%)$, diarrhea $(87.5 \%)$, and sleep disturbances $(48.2 \%)$. Only $33.2 \%$ of parents allowed their children to bite on chilled objects to relieve symptoms associated with teething. A common lack of knowledge about teething among parents should encourage dental healthcare providers to educate them regarding the teething process and its management.
\end{abstract}

Descriptors: Child; Parents; Perception; Signs and Symptoms; Tooth Eruption.

\section{Introduction}

Tooth eruption is defined as the process by which a tooth moves from its developmental position within the jaw and emerges into the oral cavity. ${ }^{1}$ The relationship between the eruption of deciduous teeth and infants' general health has been documented for more than 5,000 years. A variety of physical disturbances have historically been attributed to teething; these include pain, inflammation of the mucous membrane overlying the tooth, irritability, disturbed sleep, facial flushing, drooling, gum irritation, bowel upset, loss of appetite, and ear rubbing on the side of the erupting tooth. ${ }^{2}$

As eruption takes place over a 2.5 -year period, it is not surprising that these coincidental factors emerge. Swann ${ }^{3}$ reviewed cases of 50 children admitted to hospital with teething complaints and found that a medical condition was diagnosed in 48 children, including one case of bacterial meningitis. Baykan et al. ${ }^{4}$ evaluated parents' experience with their infants' teething in Turkey, and reported that the most frequent teething symptom was increased biting, followed by irritability and fever. In a survey of 201 infants aged 6-12 months in Calcutta, Chakraborty et al. ${ }^{5}$ found that the most common disturbance was gum inflammation, fol- 
lowed by cheek flushing, mouth ulcers, cheek rashes, and eruption cysts.

However, teething does not appear to cause diarrhea, fever, rashes, seizures, or bronchitis. It may be associated with some daytime restlessness, thumb sucking, gum rubbing, drooling, and temporary loss of appetite. It remains unclear whether these signs are developmental in origin or are actually related to tooth eruption. Illness occurring in association with teething should be evaluated thoroughly so that a serious systemic disturbance is not overlooked. ${ }^{6}$

Historically, caregivers have taken a variety of approaches to the symptomatic relief of discomfort associated with teething, including blistering, placing leeches on the gums, applying cautery to the back of the head, and administering systemic medicaments, including many opiates and poisons such as lead acetate, mercury, and bromide. ${ }^{2}$ Recently, rubbing substances onto the gums and allowing the infant to chew on hard objects have become popular practices. Chewing on clean, hard, cool objects, such as chilled teething rings and rattles, cold wet washcloths, and chilled hard vegetables, may provide relief from soreness. ${ }^{7}$ When a child experiences extreme difficulty, the additional use of topical analgesics containing choline salicylate or lidocaine hydrochloride, or powders containing benzocaine and paracetamol, may be helpful. ${ }^{8}$

Parents' false beliefs about signs and symptoms associated with teething may interfere with the prompt diagnosis and management of serious illnesses. Thus, there is a need to distinguish between facts and false beliefs associated with teething. To our knowledge, no study has been conducted in India to assess parents' knowledge, beliefs, and practices regarding their children's teething. Hence, this study was performed to assess parents' knowledge and beliefs about teething signs and symptoms and to investigate the practices used to alleviate teething troubles.

\section{Methodology}

\section{Study setting and population}

A cross-sectional study was conducted in the Department of Pediatrics, Government Medical College, Udaipur, India. All parents with children aged
6 months to 3 years who visited the Department of Pediatrics in August 2010 were surveyed. The total sample size was 550 parents. Response rate was $100 \%$.

\section{Ethical approval and official permission}

Before the commencement of the study, ethical approval was obtained from the Ethical Committee of Pacific Dental College, Udaipur. Official permission was obtained from the Head of the Department of Pediatrics, Government Medical College, Udaipur. Written informed consent was obtained from parents who were willing to participate.

\section{Pre-testing survey}

A self-administered structured questionnaire was first developed in English to facilitate its review by experts in pediatric dentistry for structure and content validity. The English version was then translated into a more viable local language (Hindi) to aid comprehension by the study population. The validity and reliability of this questionnaire were then tested with a group of 25 parents. Feedback from these parents was considered and a few questions were reframed to improve the clarity of meaning. Reliability was assessed using Cronbach's alpha coefficient (0.9).

\section{Questionnaire}

The questionnaire consisted of 31 items in three sections:

- Section I comprised seven questions about parents' and children's demographic characteristics.

- Section II contained four questions that assessed parents' general knowledge about children's teething and 14 questions that assessed parents' beliefs about teething-associated signs and symptoms.

- Section III contained six questions that investigated parents' practices in managing teething problems.

Responses to sections II and III were structured using "agree," "disagree," and "don't know" options. 


\section{Data collection}

The questionnaire was distributed to parents and collected immediately after completion. Participants' ages were classified as 20-24, 25-29, $30-34$, or $>35$ years. Education was classified as primary school, secondary school, high school certificate, post-high school certificate, or graduate/ postgraduate degree. Occupation was stratified as unemployed, unskilled worker, skilled worker, cleri$\mathrm{cal} /$ shop owner/farmer, and professional. Income was recorded on the basis of Prasad's classification of socioeconomic status. ${ }^{9}$ The number of children was classified as one, two to four, or more than four. The age of the youngest child was classified as $6-12,12-24$, or 24-36 months.

\section{Data analysis}

Data were analyzed using SPSS software (ver. 11.5; SPSS, Inc., Chicago, USA). Descriptive statistics were used to summarize the sample. Relationships between dependent (knowledge, beliefs and practices) and independent variables (demographic characteristics) were analyzed using the chi-squared test. A value of $p \leq 0.05$ was considered statistically significant.

\section{Results}

The majority of respondents were women $(60.9 \%)$ belonging to the middle socioeconomic class $(54.7 \%)$ who were unemployed $(56.9 \%)$ and had one child (51.1\%) aged 6-12 months (55.5\%). Almost half of the study population was $25-30$ years of age $(43.1 \%)$ and had a high-school level of education $(40.7 \%$; Table 1$)$.

Table 2 shows the associations between demographic variables and parents' knowledge about teething. A total of $393(71.4 \%)$ parents answered all questions correctly. The level of knowledge about teething was significantly associated with age group, with parents aged 25-30 years demonstrating better knowledge $(p<0.05)$. Education, occupation, and income showed highly significant associations with knowledge; participants who were graduates/postgraduates, professionals, and/or belonged to a higher income group had better knowledge $(p<0.01)$. Sex was not significantly related to knowledge about
Table 1 - Demographic profile of the study population.

\begin{tabular}{|c|c|c|}
\hline Variables & $N=550$ & $\%$ \\
\hline \multicolumn{3}{|l|}{ Age (years) } \\
\hline $20-24$ & 147 & 26.7 \\
\hline $25-30$ & 237 & 43.1 \\
\hline $31-34$ & 109 & 19.8 \\
\hline$>35$ & 57 & 10.4 \\
\hline \multicolumn{3}{|l|}{ Sex } \\
\hline Male & 215 & 39.1 \\
\hline Female & 335 & 60.9 \\
\hline \multicolumn{3}{|l|}{ Education } \\
\hline Postgraduate/graduate & 156 & 28.4 \\
\hline Intermediate/post-high school diploma & 93 & 16.9 \\
\hline High school certificate & 224 & 40.7 \\
\hline Middle school certificate & 65 & 11.8 \\
\hline Primary school certificate & 12 & 2.2 \\
\hline \multicolumn{3}{|l|}{ Occupation } \\
\hline Professional & 50 & 9.1 \\
\hline Clerical, shop owner, farmer & 121 & 22.0 \\
\hline Skilled worker & 53 & 9.6 \\
\hline Unskilled & 13 & 2.4 \\
\hline Unemployed & 313 & 56.9 \\
\hline \multicolumn{3}{|l|}{ Income } \\
\hline । & 98 & 17.8 \\
\hline$\|$ & 103 & 18.7 \\
\hline III & 121 & 22.0 \\
\hline IV & 182 & 33.1 \\
\hline V & 46 & 8.4 \\
\hline \multicolumn{3}{|c|}{ Number of children } \\
\hline 1 & 281 & 51.1 \\
\hline $2-4$ & 260 & 47.3 \\
\hline$>4$ & 9 & 1.6 \\
\hline \multicolumn{3}{|c|}{ Age of the youngest child (months) } \\
\hline $6-12$ & 305 & 55.5 \\
\hline $12-24$ & 131 & 23.8 \\
\hline $24-36$ & 114 & 20.7 \\
\hline
\end{tabular}

teething $(p>0.05)$.

Table 3 shows the associations between demographic variables and signs and symptoms believed by parents to be caused by teething. Parents correctly identified the desire to bite, gum irritation, in- 
Table 2 - Percentage distribution of responses regarding knowledge of teething and its association with demographic variables.

able 3 - Percentage distribution of responses regarding signs and symptoms of teething and its association with demographic variables.

\begin{tabular}{l|c|c|c}
\hline \multicolumn{1}{c|}{ Questions } & Agree & Disagree & Don't know \\
\hline $\begin{array}{l}\text { Babies' teeth start to erupt around 6-7 months of } \\
\text { age**£ }\end{array}$ & 84.0 & 9.6 & 6.4 \\
\hline $\begin{array}{l}\text { The first teeth to appear in the mouth are lower } \\
\text { central incisors }\end{array}$ & 81.3 & 15.1 & 3.6 \\
\hline $\begin{array}{l}\text { The eruption of teeth gets completed at } \\
\text { approximately 2 years of age }\end{array}$ & 76.2 & 18.9 & 4.9 \\
\hline $\begin{array}{l}\text { Delayed eruption of teeth may be an indication of } \\
\text { the presence of systemic disease }\end{array}$ & 44.7 & 31.1 & 24.2 \\
\hline
\end{tabular}

Significance was determined using the chi-squared test. Significant correlation with *parents' age $(p<0.05)$; "parents' education, occupation, and income $(p<0.01)$; Enon significant correlation with parents' $\operatorname{sex}(p>0.05)$.

\begin{tabular}{|c|c|c|c|}
\hline Items & Agree & Disagree & Don't know \\
\hline Fever*¥£ & 70.0 & 26.7 & 3.3 \\
\hline Diarrhea* ${ }^{* ¥}$ & 87.5 & 10.7 & 1.8 \\
\hline Sleep disturbance / wakefulness ${ }^{* ¥ £}$ & 48.2 & 39.3 & 12.5 \\
\hline Loss of appetite ${ }^{* \neq \varepsilon}$ & 23.8 & 59.5 & 16.7 \\
\hline Gum irritation ${ }^{* * £}$ & 81.5 & 13.6 & 4.9 \\
\hline Desire to bite ${ }^{* * \varepsilon}$ & 77.5 & 17.3 & 5.3 \\
\hline Increased salivation ${ }^{* ¥ £}$ & 51.6 & 31.8 & 16.5 \\
\hline Runny nose $e^{* ¥ £}$ & 32.7 & 51.5 & 15.8 \\
\hline Respiratory system problem ${ }^{* \neq £}$ & 4.0 & 71.1 & 24.9 \\
\hline Skin rash ${ }^{* \neq £}$ & 1.8 & 71.6 & 26.5 \\
\hline Vomiting ${ }^{* * \varepsilon}$ & 37.1 & 50.0 & 12.9 \\
\hline Ear problems ${ }^{* * \varepsilon}$ & 23.3 & 51.3 & 25.5 \\
\hline Convulsions ${ }^{* * £}$ & 1.5 & 68.0 & 30.5 \\
\hline Increased susceptibility to other diseases $* ¥ £$ & 3.6 & 64.7 & 31.6 \\
\hline
\end{tabular}

Significance was determined using the chi-squared test. Significant correlation with *parents' age, children's age $(p<0.05)$; ${ }^{*}$ parents' education $(p<0.01)$; 'non significant correlation with parents' sex and number of children $(p>0.05)$.

creased salivation, and loss of appetite as associated with teething. Almost $75 \%$ of parents incorrectly attributed fever, diarrhea, and sleep disturbances to teething, and $71.1 \%$ believed that systemic symptoms were not related to the process.

On cross-tabulation, education showed a highly significant association with knowledge of teething signs and symptoms $(p<0.01)$; participants with higher education had better knowledge of these signs and symptoms than did those with less education. A significant association was also observed with children's and parents' ages; parents with children aged $6-12$ months $(p<0.05)$ and younger parents aged $20-24$ years $(p<0.05)$ had better knowledge. In contrast, the number of children and the sex of the parent had no significant effect on knowledge about teething signs and symptoms $(p>0.05)$.

Table 4 shows the associations between demographic variables and parents' beliefs about useful practices for the management of teething problems. About $40 \%$ of parents agreed with the use of bottle feeding or nursing at night to control the symptoms of teething. Only $33.8 \%$ of parents allowed their children to bite on chilled objects, $62.7 \%$ used systemic analgesics, $45.6 \%$ rubbed the gums with topical analgesics to relieve symptoms associated with teething, $60.9 \%$ gave their children fluids to prevent dehydration, and $86.4 \%$ believed it was appropri- 
Table 4 - Percentage distribution of responses regarding practices to manage teething problems and its association with demographic variables. ate to consult with a primary healthcare provider in cases of eruption and/or teething problems. Practices were related to parents' education and income; parents with higher education and incomes demonstrated better knowledge of the practices believed to be useful for children during teething $(p<0.01)$.

\section{Discussion}

Many behavioral changes occur in the early stages of an infant's life. Parents may become concerned by these changes and wonder how to stop them. Between the ages of 4 months and 3 years, parents attribute much of children's health problems or a subset of their behavior to teething. ${ }^{3}$

In accordance with most studies, ${ }^{2,10-13}$ the present study showed that local symptoms, including the desire to bite, gum irritation, and increased salivation, were most frequently rated as symptoms associated with teething. The majority of parents in our sample had false beliefs about the signs and symptoms of teething, such as the inclusion of fever $(70 \%)$ and diarrhea $(87.5 \%)$. Other incorrectly identified symptoms included a runny nose $(32.7 \%)$, vomiting (37.1\%), and ear problems (23.3\%); almost $75 \%$ of parents believed that at least one of these symptoms was associated with teething.

Our finding that $70 \%$ of parents falsely believed that fever was associated with teething was in accordance with that of Wake et al., ${ }^{12}$ who found that $70-85 \%$ of parents believed that teething causes fever, pain, irritability, sleep disturbance, and drool- ing. The proportion of parents with this false belief in the present study was higher than that found by Feldens et al. ${ }^{14}$ (38.9\%), but lower than that found by Owais et al. ${ }^{10}(84.9 \%)$.

The timing of eruption of the deciduous incisors (6-12 months) coincides with the reduction in circulating maternal humoral immunity and the establishment of a child's humoral immunity. Most children of this age are susceptible to a myriad of relatively minor infections. The symptoms of elevated temperature, facial rash, irritability, and loss of appetite could also be due to infection with the human herpesvirus 6 (HHV-6), which is ubiquitous among infants of teething age. Several features attributed by parents to teething can be explained by alternative non-teething etiologies. ${ }^{2}$

The symptom associated second-most frequently (by $87.5 \%$ of parents) with teething was diarrhea; this proportion was much higher than those found by Wake et al., ${ }^{12}$ Owais et al., ${ }^{10}$ and Feldens et al. ${ }^{14}$ Although teething and diarrhea are not usually associated, some parents believe that their child's diarrhea is due to tooth eruption. Diarrhea may be due to the placement of contaminated objects in the mouth. However, children with "teething diarrhea" are just as likely to develop dehydration as are children with non-teething diarrhea. Thus, primary care providers should be aware of these various beliefs, educate parents to recognize the early signs of dehydration, discourage the belief that teething causes diarrhea. ${ }^{15}$ 
About half $(48.2 \%)$ of parents in the present study believed that sleep disturbance/wakefulness was associated with teething; this proportion was much lower than those found by Owais et al. ${ }^{10}$ $(80.8 \%)$ and Wake et al. ${ }^{12}$ (78\%). Vomiting (37.1\%) and convulsions $(1.5 \%)$ were attributed to teething in the present study. Such symptoms could indicate more serious health problems and call for immediate medical consultation to investigate the child's general health. ${ }^{14}$

In contrast to the above-mentioned studies, a prospective study conducted by Wake et al. ${ }^{16}$ showed that although parents and caregivers reported many of the symptoms described above, no relationship between teething and symptoms such as fever, mood disturbance, drooling, and rashes was confirmed.

Regarding parents' practices to manage teething symptoms, Wake et al. ${ }^{12}$ reported that $76 \%$ of parents used some form of medication, most commonly paracetamol $(60 \%)$ and/or teething gels $(55 \%)$; in the present study, $62.7 \%$ of parents used systemic analgesics and $45.6 \%$ rubbed the gums with topical analgesics. Only $33.8 \%$ of parents in the present study allowed their children to chew on chilled objects, and around $40.4 \%$ allowed bottle feeding or nursing at night.

Temporary pain relief is provided by the pressure produced by chewing a chilled teething ring. The cold temperature of the object causes localized vasoconstriction, which reduces inflammation, and biting on the object gives further relief by applying pressure to the gums. Other objects used include pacifiers, hard unsweetened flour biscuits, and a variety of fresh and frozen fruits and vegetables (peeled cucumber, frozen bananas). ${ }^{2}$

Parents report that pain is a common feature of teething. However, the tooth's protrusion through the bone does not contribute to this pain, as commonly believed by laypeople; rather, the dental follicle, which is a rich source of cytokines and growth factors, is responsible for the localized inflammatory response and pain. Thus, the etiology of teething symptoms can usually be traced to one of the many childhood illnesses. ${ }^{17}$

The association observed between teething outcome and per capita income showed that families with high socioeconomic status take better care of their children, which was in accordance with the findings of Feldens et al. ${ }^{14}$ These parents may have positive health attitudes that include paying more attention to symptoms that appear during the first year of life.

It is perhaps going a bit too far to say that "teething produces nothing but teeth," but disastrous errors are still made by ascribing a child's symptoms to teething. This perspective may result in negative health outcomes, such as the hospital admission of an infant who is moribund due to pyogenic meningitis and convulsions that had been ascribed to teething. ${ }^{16}$

Because our findings were obtained in a pilot study conducted in a single locality, our conclusions cannot be applied to the general population. A more sophisticated survey with a larger population size that includes multiple geographical areas is required. However, our preliminary findings indicate that the majority of parents incorrectly attributed fever, diarrhea, vomiting, and sleep disturbances to teething. Thus, before ascribing any sign or symptom of a potentially serious illness to teething, parents must learn to rule out other possible causes; this could be accomplished by making accurate information available to increase parents' competence. Scientific information about teething should be included in health educational packages directed at different subpopulations within communities. Communities would benefit if parents underwent frequent, compulsory, standardized training on oral health-promoting factors. Pediatricians can also utilize the opportunity to educate parents about their role in improving their children's oral health during antenatal checkups and immunization visits.

\section{Conclusion}

This study identified parental misconceptions about teething signs and symptoms. Pediatricians must review and dispel long-held cultural myths and beliefs about teething, acknowledge and share the evidence that tooth eruption is not strongly associated with significant symptoms, and begin to manage the issues of late infancy and toddlerhood more effectively. 


\section{References}

1. Craddock HL, Youngson CC. Eruptive tooth movement - the current state of knowledge. Br Dent J. 2004 Oct 9;197(7):38591.

2. McIntyre GT, McIntyre GM. Teething troubles? Br Dent J. 2002 Mar 9;192(5):251-5.

3. Swann IL. Teething complications, a persisting misconception. Postgrad Med J. 1979 Jan;55(639):24-5.

4. Baykan Z, Sahin F, Beyazova U, Ozcakar B, Baykan A. Experience of Turkish parents about their infants' teething. Child Care Health Dev. 2004 Jul;30(4):331-6.

5. Chakraborty A, Sarkar S, Dutta BB. Localised disturbances associated with primary teeth eruption. J Indian Soc Pedod Prev Dent. 1994 Mar;12(1):25-8.

6. Leung AK. Teething. Am Fam Physician. 1989 Feb;39(2):1314.

7. Ashley MP. It's only teething.... a report of the myths and modern approaches to teething. Br Dent J. 2001 Jul 14;191(1):4-8.

8. Wilson PH, Mason C. The trouble with teething--misdiagnosis and misuse of a topical medicament. Int J Paediatr Dent. 2002 May;12(3):215-8.

9. Agarwal A. Social classification: the need to update in the present scenario. Indian J Community Med. 2008 Jan;33(1):50-1.

10. Owais AI, Zawaideh F, Bataineh O. Challenging parents' myths regarding their children's teething. Int J Dent Hyg. 2010 Feb;8(1):28-34.
11. Macknin ML, Piedmonte M, Jacobs J, Skibinski C. Symptoms associated with infant teething: a prospective study. Pediatrics. 2000 Apr;105(4 Pt 1):747-52.

12. Wake M, Hesketh K, Allen M. Parent beliefs about infant teething: a survey of Australian parents. J Paediatr Child Health. 1999 Oct;35(5):446-9.

13. Cunha RF, Pugliesi DM, Garcia LD, Murata SS. Systemic and local teething disturbances: prevalence in a clinic for infants. J Dent Child (Chic). 2004 Jan-Apr;71(1):24-6.

14. Feldens CA, Faraco IM, Ottoni AB, Feldens EG, Vitolo MR. Teething symptoms in the first year of life and associated factors: a cohort study. J Clin Pediatr Dent. 2010 Spring;34(3):201-6.

15. DenBesten P. Is teething associated with diarrhea? West J Med. 2000 Aug;173(2):137.

16. Wake M, Hesketh K, Lucas J. Teething and tooth eruption in infants: A cohort study. Pediatrics. 2000 Dec;106(6):1374-9.

17. Shapira J, Berenstein-Ajzman G, Engelhard D, Cahan S, Kalickman I, Barak V. Cytokine levels in gingival crevicular fluid of erupting primary teeth correlated with systemic disturbances accompanying teething. Pediatr Dent. 2003 SepOct;25(5):441-8. 